\title{
Public grief: The Hip
}

$\mathrm{G}$ ord Downie, the lead singer of The Tragically Hip, has brain cancer. In a year when we have already lost Bowie, Prince, Guy Clark and Ron Hynes - another musical giant might be leaving us.

Like many 40-something Canadians, the lyrics of The Hip have been gospel for me for decades. I listened to their Road Apples album all through the latter part of undergrad, when I was starting to figure myself out. I listened on the drive from Calgary to Kingston - The Hip's hometown to start grad school. I was leaving my childhood home on the Prairies, the place Downie and his band captured with such truth: "And all you hear are the rusty breezes/Pushing around a weather vane Jesus."

As a young writer, I dreamt of capturing the Prairies like only Downie could sing about them. There was their show in a Kingston hockey rink: my friends and I in our regulation denim and plaid. The time I thought I spotted him near the hole-in-the-wall restaurant I frequented on King Street. Fiddler's Green, the first and last song I ever attempted at an open mic, fumbling to find the exact location of its soul.

Just songs maybe. More like poems pinned to the Gzowskian bulletin board of the nation.

Fittingly, I hear the news on CBC, while feeding morning crepes to my three small kids, who have no idea why I'm suddenly glassy eyed. How can I tell them I feel closer to death myself? That time is passing, and there is a hole in me because of something happening to someone I've never met? I drive to work, thinking of circles of meaning

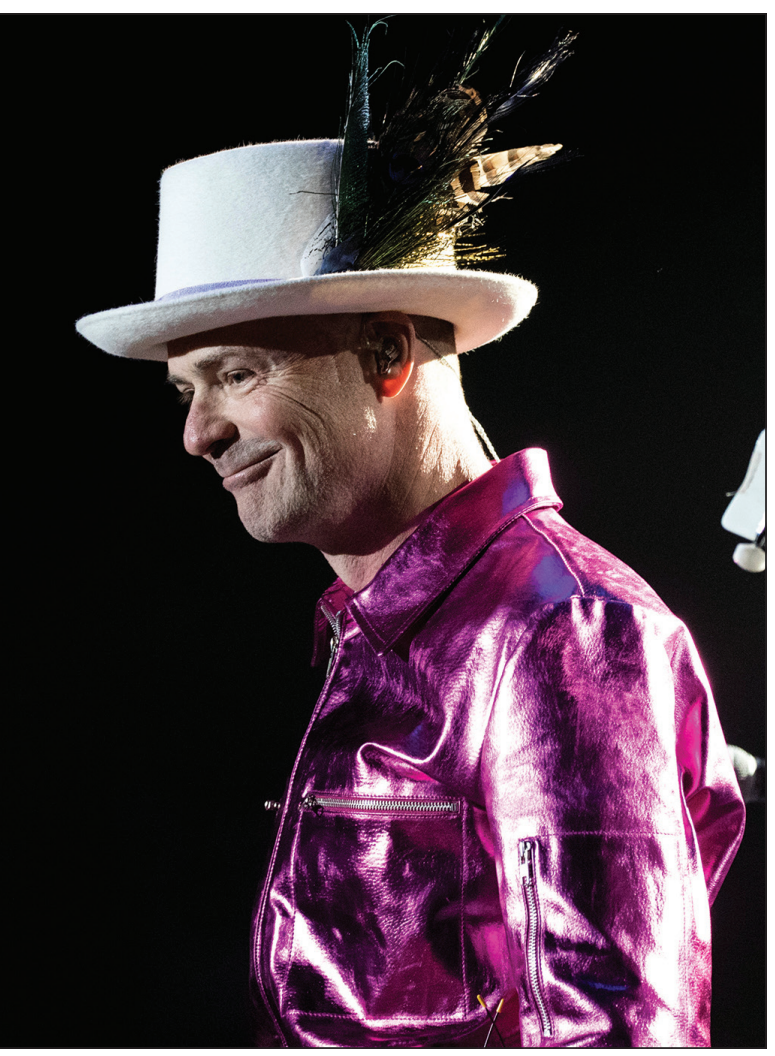

The Tragically Hip lead singer Gord Downie performing in Victora, BC, July 22, 2016.

and grief. Private, public. The private grief of Gord Downie and his family. The public grief that we, his fans, are sharing. Wondering what right I have to feel part of his story.

Later in the day, I tell a woman she most likely has cancer. There are tears and disbelief and questions. Toward the end of our conversation, her husband says, "This is hard for you." Meaning me, their doctor. I wave away his comment, amazed that he would see that, in the midst of everything. They leave. I try to $\log$ on to the computer to write my note and see that my own hands are trembling. Someone hovers next to me, eyeing my attempts to type.

What right do we have to feel grief for another, when their own grief their own physical pain — is so alive?
When I write about a patient, I need their consent. Patients tell me things that they wouldn't otherwise unless they knew I would keep their confidence. I like to think that consent is also about making sure my meaning doesn't trump theirs. Perhaps my grief is a mark of their personhood? Or a hard lesson learned that will help me care for others in the future? Who really cares, when someone's world is collapsing, now. Yet, I, too, am changed in the face of another's suffering. Whose story is that?

On my bike ride home along the river, I pass a little boy, no more than four, furiously pedalling on what must be his first bike. A couple, about the age of my patient and her husband, is strolling in the evening sunshine. A kid whose hair seems big enough to lift him right up off of his skateboard. Snapshots of lives, whipping by. No time to stop. No time to wonder.

My kids, when they have finished eating crepes at my kitchen table, will have their own heroes who will grow old and die, or who will fall from grace and leave them lonely. They will build ramparts of hope, they will see themselves in others, they will hurt for them. I want them to know that grief binds us together, even if it means throwing sloppy handfuls of meaning at the void. "Now the struggle has a name/We are the same It hasn't changed."

\section{Monica Kidd MD}

Department of Family Medicine, University of Calgary, Calgary, Alta.

This article has been peer reviewed.

CMAJ 2016. DOI:10.1503/cmaj.160942 